\title{
Questionando a desigualdade
}

\author{
Igor Zanoni Constant Carneiro Leão*
}

RESUMO - O crescimento econômico mundial repercutiu no Brasil de forma bastante favorável para o produto interno e o mercado de trabalho, levando a uma melhoria na tradicionalmente aguda desigualdade social no país. Este texto levanta dados indicando essa melhoria. Entretanto mostra também o quadro precário ainda existente entre os trabalhadores de um mercado de trabalho heterogêneo e marcado por baixos salários. Defende-se aqui que qualquer enfrentamento desses problemas passa por uma revisão mais profunda do que analistas do desenvolvimento latino americano denominavam estilo de crescimento e que tem a ver com políticas públicas diversas mais finas e avançadas que as políticas ainda insuficientes na área previdenciária e do Bolsa Família.

Palavras-chave: Mercado de trabalho. Desigualdade. Políticas públicas.

O bom desempenho do mercado de trabalho e políticas na área previdenciária e de transferência de renda tem revelado um aparente sucesso frente à desigualdade social marcante no país. Dados recentes do IPEA revelam que em 2007 o bom panorama macroeconômico, apresentando um crescimento do produto de 5,7\% ligado ao crescimento das exportações e das atividades industriais é responsável por esse bom desempenho. Ocorreu uma elevação expressiva do nível de ocupação em 2007 e o menor índice de informalidade desde a implantação da nova metodologia da Pesquisa Mensal de Emprego - PME. Tudo isso com uma inflação anual de 4,5\% que é o centro da meta estipulada pelas Autoridades Monetárias.

Houve um incremento médio do nível de ocupação em 2007 de 3\%, representando 623 mil novos postos de trabalho com a indústria e o comércio criando percentualmente menos postos, mas se recuperando no final do ano frente às demais áreas do mercado. As regiões metropolitanas pesquisadas pela PME destacam a RM de São Paulo com 289 mil novas vagas ou $46 \%$ do total das vagas criadas ao longo do ano e 42,4\% de participação no total da pesquisa, num contexto de crescimento global das RM.

Em termos de faixa etária houve uma redução no contingente ocupado de 15 a 17 anos em $6,5 \%$, crescimento de $59,2 \%$ na faixa entre 25 e 49 anos e de $36,2 \%$ na faixa acima de 50

\footnotetext{
* Doutor em Economia pela UNICAMP. Professor do departamento de Economia pela Universidade Federal do Paraná (UFPR). Endereço eletrônico: igorzaleao@yahoo.com.br
} 
anos. Estas duas últimas faixas representaram 95,4\% da expansão da ocupação em 2007 e 82,5\% da força de trabalho ocupada. O crescimento beneficiou os grupos mais escolarizados, pois foram criados 76 mil postos de trabalho para trabalhadores com 8 a 10 anos de estudo e 690 mil para trabalhadores com 11 ou mais anos de estudo.

Por outro lado, houve um decréscimo de $0,6 \%$ no trabalho informal, embora tenha havido um crescimento de 4,2\% no trabalho autônomo. Houve também decréscimo dos subocupados e sub-remunerados. A taxa de desemprego média ficou em 9,3\% caindo 0,7\% para homens e 0,6\% para mulheres. Houve também crescimento de 3,2\% das médias anuais de rendimento. O trabalho sem carteira assinada aumentou seu número em 8,5\% e com carteira em $1 \%$, totalizando um aumento de 3,2\%. A massa de salários elevou-se em 6,25\%.

Segundo Márcio Pochmamn, a pobreza no país se reduziu bem como a indigência. A pobreza nas seis regiões metropolitanas pesquisadas apresentou $17 \%$ da população e os mais ricos, ou seja, os que recebem mais de 16 mil e seiscentos reais passaram de 448 mil para 471 mil pessoas. Há também entre esses pólos uma classe média em expansão. A renda familiar é representada em $90,7 \%$ por rendimentos do trabalho e aposentadorias, $7,2 \%$ por pensão, doação e aluguel e 2,1\% do Bolsa Família. Esta renda é basicamente de atividades laborais.

A queda da pobreza explica a menor desigualdade da renda do trabalho. A PME revela queda de 35\% da população pobre em 2003 para 24\% em 2008. A indigência cai para metade em número de indivíduos, entretanto, ainda há 4 milhões de pobres em São Paulo e 2,6 milhões no Rio de Janeiro, embora seu número tenha se reduzido. A RM de São Paulo abriga 35,7\% dos pobres no país e a do Rio de Janeiro, 22,3\%. Observa-se também um incremento de 28,1 mil pessoas consideradas ricas a mais que em 2002. A classe média, considerada a faixa que recebe entre $\mathrm{R} \$ 1.064$ e $\mathrm{R} \$ 4.591$ representa $52 \%$ da população. Todos estes dados constam da base de dados do IPEA e do IBGE e podem ser consultados nos sites respectivos. Eles indicam uma sensível melhora na desigualdade histórica que marca o país graças ao bom funcionamento do mercado de trabalho e do crescimento econômico no interior de um crescimento mundial. Mostram também a importância da previdência para os aposentados, na qual se destaca a elevação nos últimos anos do salário mínimo real e as transferências de renda do Bolsa Família. Nota-se, entretanto, a importância várias vezes maior dos gastos com a previdência em relação com a Bolsa Família, algo nem sempre notado nos debates sobre a desigualdade. 
Podemos fazer, entretanto, alguns contrapontos ao panorama acima. Se tomarmos os indicadores do Dieese, o salário mínimo necessário em maio de 2008 alcançava $\mathrm{R} \$ 1.987,51$ contra o salário mínimo do governo de apenas $\mathrm{R} \$ 415$. Isso mostra o quanto estamos distantes realmente de um melhor equacionamento da desigualdade e da pobreza. O nível de renda inicial da classe média para o IPEA é bem inferior ao salário mínimo necessário do Dieese. Na verdade, ele é também inferior ao rendimento médio dos ocupados em São Paulo em maio de 2008 que era de apenas $\mathrm{R} \$ 1200$, ou $\mathrm{R} \$ 1279$ para a média dos assalariados. Esses dados são representativos quando se pensa que o mercado de trabalho está fraturado em $60 \%$ de trabalhadores informais e $40 \%$ de trabalhadores formais. Embora não necessariamente, o trabalhador informal recebe menos e tem muito mais insegurança no trabalho, associado ao menor elenco de direitos sociais de que dispõe.

Esses dados todos têm levado a diversos debates na mídia, assim, o economista Marcelo Néri da FGV anunciou na Folha de São Paulo que as famílias de classe média subiram proporcionalmente de 42,26\% para 51,89\% entre 2004 e 2008 como se lê em coluna de Kennedy Alencar no site do jornal. Pegando o bonde, o economista Paulo Rabello de Castro, no artigo $A$ Nova Classe Média Mundial, publicado também na Folha de São Paulo em 13/08/2008, afirma de que segundo projeções da Dominic Wilson, a classe média mundial terá 2 bilhões de pessoas a mais nos próximos 22 anos, em torno de 80 milhões entrantes por ano. O salto na classe média brasileira deve-se ao empurrão mundial mais que as políticas internas. Segundo o economista, o Brasil precisa, para efetivar uma distribuição de renda mais rápida, baixar juros e melhorar a educação.

Creio que essa opinião dá muita ênfase ao crescimento do mercado sem ver que esse mercado vem sendo tutelado pelas políticas macroeconômicas dos grandes países do mundo, inclusive o Brasil e que ele se constitui também em uma construção social. É difícil criar mercados e eles não nascem no vazio das instituições privadas e públicas. Além disso, o autor poderia mostrar a necessidade das políticas brasileiras sustentarem melhor esses mercados, não apenas com menores juros, mas também com câmbio mais adequado que o atual e políticas diversas como veremos adiante. Também não é possível esquecer o papel que a previdência e o Bolsa Família vêm prestando para os mais desafortunados.

É preciso também lembrar que segundo a metodologia do Dieese na sua Pesquisa de Emprego e Desemprego nas seis regiões metropolitanas pesquisadas havia uma taxa de 
desemprego em junho de 14,6\%, significando 2.899 .000 pessoas desempregadas e 17.004.000 ocupados. Dependendo da metodologia há entre dois e quase três milhões de pessoas desempregadas, o que é um número que atesta a fragilidade que ainda persiste no mercado de trabalho.

É preciso ainda fazer algumas considerações adicionais sobre renda e trabalho no Brasil. A primeira se refere à Previdência. Esta foi consolidada no final dos anos $80 \mathrm{com}$ a Constituição de 88 na contramarcha do cenário neoliberal inovando como parte da Seguridade Social, integrada por Saúde, Previdência Social, Assistência Social e Seguro Desemprego. Seu fundamento é a solidariedade social, que implica que os impostos que deveriam ser pagos pelos mais ricos financiariam os direitos dos indivíduos mais vulneráveis. Com isto, se abriu a todos os cidadãos o Sistema Único de Saúde, aposentadorias para 7 milhões de trabalhadores rurais e 3 milhões de beneficiários da Lei Orgânica de Assistência Social (LOAS). Com isto se criou um embrião de um Estado de Bem-Estar Social baseado nos princípios da universalidade, da solidariedade, da seguridade e da compreensão da questão social como um direito da cidadania. Esse embrião precisa ser consolidado na medida em que vem sendo atacado pelos defensores do Estado Mínimo, que procura enterrar as conquistas sociais de 1988.

Esse ponto é importante porque os dados da Pnad só captam a renda do trabalho e não se sabe de fato qual é a distribuição de renda no Brasil. Além disso, é muito discutível quem está abaixo da linha da pobreza no Brasil. O Banco Mundial arbitrou a linha de pobreza em meio salário mínimo mensal, mas é evidente que esse é um número muito baixo, incompatível com a vida numa grande metrópole. Por outro lado, o gasto anual com o programa Bolsa Família é de cerca de 10 bilhões de reais, contra mais de 160 bilhões reais de gastos com o INSS e a Previdência Rural. Esses dados mostram a importância da Previdência para a construção de um país democrático de fato. Esses dados podem ser encontrados em Carta Social e do Trabalho, CESIT/Unicamp, no 07, setembro a dezembro de 2007.

Mas falta aperfeiçoar a previdência, por exemplo, as atuais regras de idade mínima pra aposentadoria são muito elevadas para o Brasil. O SUS encontra-se hoje muito fragilizado e há necessidade de revisar o projeto de regulamentação da seguridade social. Existe um grande interesse do setor financeiro na previdência complementar, que olha gulosamente para os recursos da previdência. As aposentadorias também sofrem com a aplicação de um fator previdenciário que abaixou em quase $1 / 4$ os valores das aposentadorias. $O$ teto dos benefícios, 
hoje em R $\$ 3038,99$ é irreal para a classe média que se deseja estar surgindo no Brasil. É preciso também fazer com que o sistema previdenciário não seja obstaculizado em seu financiamento pela informalidade, o desemprego, e a rotatividade do trabalho.

Outro elemento que incide fortemente sobre a desigualdade são as imperfeições do sistema tributário brasileiro. Este continua fortemente baseado em impostos que incidem sobre o consumo, regressivos porque as famílias de menor rendimento despendem uma parte maior dele com consumo de mercadorias enquanto os mais ricos gastam relativamente mais com serviços que são subtributados e ainda possuem capacidade de poupar renda que não é atingida pela tributação indireta. A estrutura tributária é regressiva porque a carga tributária diminui com a elevação do nível de renda. Mesmo o imposto de renda tem hoje poucas faixas de renda, reduziuse a alíquota mais alta e a tabela não é corrigida integralmente, sobrecarregando os assalariados de nível médio de rendimento. A carga tributária representa hoje um terço do produto, elevando-se em função do crescimento econômico após 2003, mas há isenção no imposto de renda sobre capital financeiro e os princípios da capacidade contributiva, pessoalidade e isonomia tributária não são observadas de fato, favorecendo a concentração de renda e riqueza.

Nos primórdios da industrialização brasileira, pensadores progressistas ligavam o desenvolvimento ao aumento da produtividade do trabalho ligado à maior capitalização e pensavam que isto era suficiente para enxugar o trabalho sem emprego e a heterogeneidade social. À medida que isto se foi revelando ilusório, pensadores como Aníbal Pinto e Jorge Graciarena passaram a investigar os estilos de desenvolvimento econômico na América Latina. Também os pensadores ligados à teoria da dependência tentaram explicar as dificuldades em tornar um país já bastante industrializado justo e equânime.

Muitas vezes o debate econômico centra-se nos indicadores do produto e da inflação, sem advertir que os grupos sociais que se beneficiam com o crescimento em geral são os mesmos: as grandes empresas internacionais, os grandes bancos, o agronegócio e os donos de terra urbana. Os grandes atores políticos quase sempre são o capital financeiro e a mídia. Isto pode dar indicações sobre o estilo de desenvolvimento adotado pelo Brasil, do qual parece difícil se livrar apesar dos indicadores favoráveis observados atualmente no mercado de trabalho.

Falta, para combater a desigualdade, uma intervenção pública mais eficiente em inúmeros pontos do tecido econômico e social. Um exemplo: com recente crescimento tem crescido muito o preço da terra urbana e dos aluguéis e o preço de residências nas maiores 
metrópoles brasileiras. Entretanto, o investimento público em moradias populares é muito baixo e o zoneamento e as políticas urbanas municipais são claramente ineficientes ou contra os pobres.

Da mesma forma o transporte coletivo está longe de merecer prioridade entre as políticas urbanas. Todos os grandes municípios e regiões metropolitanas estão marcados hoje pelo trânsito congestionado que se acresce ao agudo problema da violência urbana. Esses problemas estão ligados a um estilo de crescimento sem criatividade cultural própria e sem cuidado para com a pessoa humana. Nesse sentido eles se somam aos ainda graves problemas pendentes no mercado de trabalho bem como os outros aqui mencionados.

A meu ver sobram problemas de difícil equacionamento para que se pense no Brasil como uma sociedade nacional no sentido que o termo tinha para Caio Prado Júnior e Celso Furtado, isto é, uma sociedade igualitária e democrática marcada por laços de solidariedade dados por uma cultura comum. Este é um alvo do qual estamos muito distantes.

\section{REFERÊNCIAS}

CASTRO, P. R. A Nova Classe Média Mundial. Folha de São Paulo. 13/08/2008.

CESIT/Unicamp. Carta Social e do Trabalho. No 07, setembro a dezembro de 2007.

Pesquisa Mensal de Emprego (PME). Rio de Janeiro: Instituto Brasileiro de Geografia e Estatística (IBGE). Disponível em: http://www.sidra.ibge.gov.br/bda/pesquisas/ pme/default.asp. Acesso em: 20/08/2008.

Pesquisa Nacional por Amostras de Domicílios (PNAD). Rio de Janeiro: Instituto Brasileiro de Geografia e Estatística (IBGE). Disponível em: http://www.sidra.ibge.gov.br/pnad/ default.asp. Acesso em: 15/08/2008.

POCHMANN, M. Atlas da exclusão social. São Paulo: Cortez, 2005. v. 5.

Salário Mínimo Necessário. Departamento Intersindical de Estatística e Estudos Econômicos (DIEESE). São Paulo. Disponível em: http://www.dieese.org.br $/ \mathrm{rel} / \mathrm{rac} / \mathrm{salminset08.xml.}$ Acesso em: 10/08/2008. 